\title{
A 20-year retrospective study of osteoarticular tuberculosis in a pediatric third level referral center
}

\author{
Napoleón González Saldaña', Mercedes Macías Parra², Luis Xochihua Díaz', Martin Palavicini Rueda, \\ Ana Jocelyn Carmona Vargas ${ }^{1}$, José Iván Castillo Bejarano ${ }^{1}$, Quetzalli Veloz Corona ${ }^{4}$, Hugo Juárez Olguín ${ }^{4,5^{*}}$ and \\ Juan Luis Chavez Pacheco ${ }^{4}$
}

\begin{abstract}
Purpose: The objective of the present study is to describe the clinical, diagnostic, radiological and therapeutic aspects of osteoarticular tuberculosis (OATB) in patients in a tertiary pediatric hospital, to know if the diagnosis of OATB in pediatrics is a challenge due to its insidious clinical presentation.

Methods: A retrospective, descriptive study of the cases of Tuberculosis (TB) in children was carried out. A total of 159 cases met the condition for the analysis.

Results: The most frequent TB modality was extrapulmonary in $85 \%$. Out of this, only $29 \%$ was OATB. The mean age was 4.9 years (range 8 months-16 years). Eighty-six per cent of cases received Bacille Calmette-Guérin (BCG) vaccination at birth. Median time of symptoms prior to diagnosis was 8 months. Microbiological confirmation was achieved only in five cases, with a high sensitivity to the antimicrobial treatment. Mycobacterium bovis BCG strain Tokio 172 was confirmed in three cases. Mortality rate was $0 \%$ during the time of study

Conclusion: Our study describes the epidemiological characteristics of OATB cases in Mexican children. This data revealed a high prevalence of bone and joint TB infection. Pediatric OATB should be considered in cases with lytic bone lesions, fever and local pain. In countries with BCG immunization program, M. bovis should not be forgotten as an etiological agent. The low detection rate with one technique approach highlights the urgent need for more sensitive test to diagnose OATB in children.
\end{abstract}

Keywords: Children, Diagnosis of tuberculosis, Epidemiology, Osteoarticular tuberculosis

\section{Introduction}

Tuberculosis is a disease that has been in existence for centuries, with report of skeletal lesions in early Neolithic population [1]. The causative agent is the bacillus Mycobacterium tuberculosis, a strict aerobic microorganism,

*Correspondence: juarezol@yahoo.com

${ }^{4}$ Laboratorio de Farmacología, Instituto Nacional de Pediatría, Avenida Imán Nº 1, 3rd piso Colonia Cuicuilco, CP 04530 Mexico City, Mexico

Full list of author information is available at the end of the article alcohol-acid resistant first described on 24th March, 1882 by Robert Koch.

TB has been a persistent global health problem with annual incidence rate of approximately 10 million cases, and one of the 10 leading causes of death in the world. In the last 5 years, it has been the leading cause of death by specific infectious agent, even above human immunodeficiency virus (HIV) [2].

The latest global report indicated that a total of 10.4 million peoples are infected and that out of these, $6 \%$ corresponds to children under 18 years of age. In the 
pediatric population, the most frequent site affected is the lung in $80 \%$. Of the extrapulmonary presentations, $67 \%$ corresponds to lymph node $\mathrm{TB}, 13 \%$ to meningeal, $6 \%$ to pleural, $5 \%$ to miliary, and $4 \%$ to musculoskeletal manifestations [3]. Of the total cases of $\mathrm{TB}$ infection, osteoarticular involvement represents $4 \%$ to $5 \%$ with reports in the pediatric population of up to $7 \%$. The diagnosis of extrapulmonary tuberculosis in the pediatric age is a challenge, since it presents with insidious onset without constitutional signs and symptoms in up to $72 \% \mathrm{~m}$ [4]. The objective of the present study is to describe the clinical, diagnostic, radiological and therapeutic aspects of OATB in patients in a tertiary pediatric hospital.

\section{Methods}

This is a retrospective, descriptive study of the cases of Tuberculosis diagnosed in the Infectious Diseases Department of National Institute of Pediatrics, Mexico City from 1999 to 2018. The hospital has a unique program of Tuberculosis in Pediatrics and all the patients with TB diagnosis are directly managed by personnel who are specialists in the disease. We collected demographic data, BCG vaccination status, clinical presentation, imaging studies, performance of purified protein derivative (PPD), diagnostic time and method, medicalsurgical treatment and follow up. Those patients who do not comply with previous criteria were excluded. HIV testing with ELISA was performed to detect immunodeficiencies. The operative procedure varied according to the case and comprises of arthrotomy and debridement, cryotherapy, application of bone substitutes (glass $\mathrm{BONE}^{\mathrm{TM}}$ ) and decompression with column stabilization. All methods were carried out in accordance with relevant guidelines and regulations under Ethics approval and consent to participate. As this was a retrospective study, all the information was obtained from the electronic records of the patients. However, the study was submitted to and approved by the Institutional Ethics and Academic Committee of National Institute of Pediatrics. Written informed consent was obtained from a parent or guardian for participants under 16 years old. The study was carried out with strict adherence to the ethical principles enunciated in the Declaration of Helsinki and to the CONSORT guidelines, http://www.consort-state ment.org/consort-2010.

Two definitions of cases were used: (1) Confirmed case is defined as the presence of positive isolation of $\mathrm{Myco-}$ bacterium tuberculosis complex in sputum; or in bone puncture fluid or tissue in a case with bone and joint infection; or a Ziehl-Neelsen (ZN) staining histologically compatible or positive; or Xpert MTB/RIF ${ }^{\circledR}$ positive and (2) probable case defined as the presence of 3 or more of the following criteria: (a) patient with consistent clinical data such as cough, fever and loss of weight, (b) compatible osteoarticular radiological image and/or Phemister's triad (juxta-articular osteoporosis, peripheral bone erosion and decreased joint space), (c) positive contact, (d) $P P D \geq 10 \mathrm{~mm}$ and (e) favorable evolution with the onset of empirical anti-TB treatment. The conventional sites of affection were considered as (i) vertebral, (ii) hip, (iii) femur and (iv) knee.

\section{Statistical analysis}

All data were statistically analyzed with SPSS system, version 21 (IBM). Descriptive statistics was used to report the characteristics of the population. The categorical variables were reported in percentages while the central tendency and dispersion measures, considered more appropriate, were used for the continuous variables. In addition, the $\mathrm{X}^{2}$ test was used. Values of $p<0.05$ were taken to be statistically significant.

\section{Results}

\section{Demographic characteristics}

In the period from 1999 to 2018, 169 cases of Tuberculosis were diagnosed and out of this, 10 were excluded for incomplete information and follow-up. The presentation of TB was extrapulmonary in 144 cases $(85 \%)$ out of which $43(29 \%)$ presented involvement at osteoarticular level without significant difference in the gender distribution (boys $65 \%$ vs. girls $45 \%$ ). The age range was from 8 months to 18 years with an average of 4.9 years. 35 $(81.3 \%)$ of the cases occurred in children $<6$ years old, 4 (9.3\%) in those between 7 and 12 years and 5 (11.6\%) in the patients between 13 and 16 years. In compliance with the national vaccination system of our country, $86 \%$ of the patients had a vaccination scheme with BCG applied at birth. $87 \%$ of the cases did not present comorbidities.

\section{Clinical presentation and location}

Table 1 summarizes the clinical, microbiological and radiological characteristics of the patients. In patients with OATB; the most common symptoms were pain which was typically somatic and badly located in all the cases; fever in $37 \%$ of the cases $(n=16 / 43)$; astheniaadynamia in $27 \%$ of the cases $(n=12 / 43)$ and edema in 9\% $(n=4 / 43)$. All patients with Pott's disease at the time of diagnosis presented a deformity of the spine cord. The average time of diagnosis of the cases was 8 months with a range of 1 to 48 months. Contact study was positive in $10(23 \%)$ of the cases. The positive contact history did not decrease the time of the diagnosis $(p<0.05)$. Tuberculin test was performed in 11 cases (test sensitivity $45 \%$ ). All patients were assessed in search of primary immunodeficiencies such as chronic granulomatous disease (CGD), interleukin 12-interferon gamma axis 
Table 1 Clinic and microbiological characteristics and sites of bone lesion

\begin{tabular}{|c|c|}
\hline Clinical characteristics & n (\%) \\
\hline Mean duration of symptoms prior diagnosis & $\begin{array}{l}8 \text { months (range } \\
1-48 \text { months) }\end{array}$ \\
\hline Symptoms & $n(\%)$ \\
\hline Pain & $43(100 \%)$ \\
\hline Fever & $16(37 \%)$ \\
\hline Loss of weight & $2(4 \%)$ \\
\hline Edema of the joint & $4(9 \%)$ \\
\hline Axial ${ }^{a}$ deformity & $19(44 \%)$ \\
\hline Asthenia - adynamia & $12(27 \%)$ \\
\hline Myalgia & $3(7 \%)$ \\
\hline Headache & $1(2 \%)$ \\
\hline Cough & $1(2 \%)$ \\
\hline Abdominal pain & $1(2 \%)$ \\
\hline \multicolumn{2}{|l|}{ Microbiology } \\
\hline Culture $(+)^{\mathrm{b}}$ & $5(15 \%)$ \\
\hline Ziehl-Neelsen staining $(+)^{\mathrm{b}}$ & $5(29 \%)$ \\
\hline $\operatorname{PCR}(+)^{b}$ & $5(55 \%)$ \\
\hline Histology (+) & $38(97 \%)$ \\
\hline $\operatorname{PPD}(+)^{\mathrm{b}}$ & $14(46 \%)$ \\
\hline Positive contact $(+)^{b}$ & $10(23 \%)$ \\
\hline \multicolumn{2}{|l|}{ Sites of bone lesion } \\
\hline Thoracic column & $14(32 \%)$ \\
\hline Lumbar column & $4(9 \%)$ \\
\hline Hip & $6(14 \%)$ \\
\hline Knee & $5(12 \%)$ \\
\hline Costal grill & $3(7 \%)$ \\
\hline Femur & $2(5 \%)$ \\
\hline Talus & $1(2 \%)$ \\
\hline Radius & $1(2 \%)$ \\
\hline Tibia & $1(2 \%)$ \\
\hline Maxilla & $1(2 \%)$ \\
\hline Humerus & $1(2 \%)$ \\
\hline \|liac & $1(2 \%)$ \\
\hline Ankle & $1(2 \%)$ \\
\hline Elbow & $1(2 \%)$ \\
\hline \multicolumn{2}{|l|}{ Surgical treatment } \\
\hline 1. Curettage plus cryotherapy & $30(70 \%)$ \\
\hline 2. Arthrodesis & $8(19 \%)$ \\
\hline 3 Placement of glass BONE ${ }^{\mathrm{TM}}$ & $3(7 \%)$ \\
\hline 4. Curettage with placement of cement & $1(2 \%)$ \\
\hline \multicolumn{2}{|l|}{ Medical treatment } \\
\hline 1. Completed treatment & $39(90 \%)$ \\
\hline 2. Currently in therapy & $3(7 \%)$ \\
\hline Median duration of completed treatment & 13 months \\
\hline 1. Median duration of intensive phase & 3.9 months \\
\hline 2. Median duration of maintenance phase & 9.1 months \\
\hline Mortality & $0 \%$ \\
\hline
\end{tabular}

${ }^{a}$ The axial deformity was reported only for the cases of Pott's disease ${ }^{b}$ Culture, Ziehl-Neelsen staining, PCR, PPD and positive contact study was performed in all the cases defect and infection by HIV, without finding any of these pathologies.

The location of the infections was in conventional sites in $76 \%$ of the cases $(n=33 / 43)$. Column involvement occurred at thoracic level (T5-T9) in 32\% of the cases $(n=14 / 43)$ followed by lumbar affectation in $9 \%$ $(n=4 / 43)$ and a case in the cervical level. All the cases of lumbar involvement presented concomitant dorsal affectation. The rest of the cases occurred in unusual sites. The sites of the TB cases were not related with age or sex of the patients $(p>0.05)$.

\section{Radiology}

Chest radiographs were performed in all the cases with pathological data. According to imaging studies conducted in the sites of affectation, the most common findings were osteolytic lesion in all the cases and abscess in $70 \%$ of the cases. Phemister's triad was observed in $9 \%$ of the cases $(n=4 / 43)$.

According to TC studies for Pott's disease, the most common findings were osteolytic lesion, kyphosis and spinal cord compression in all the cases, while vertebral abscess occurred in $34 \%(n=15 / 43)$.

\section{Diagnostic and microbiological studies}

TB confirmation in the patients was performed by culture in 5 cases (sensitivity 15\%), ZN staining in 5 cases (sensitivity 29\%) and Polymerase chain reaction (PCR) in 9 cases (sensitivity 55\%). Only one case had a positive culture and PCR results. The isolates reported in the culture were $M$. tuberculosis in sputum, M. Tuberculosis complex in 2 cases and 3 strains of $M$. bovis BCG Tokyo 172 (reported as adverse effect of the vaccine). Of the patients with negative culture, TB compatible biopsy with a sensitivity of 975 was observed in all cases. Only one case was defined as probable due to compliance with $\mathrm{PDD} \geq 15 \mathrm{~mm}$, isolation of $M$. Tuberculosis in sputum, imaging studies with compatible clinical data and also a favorable evolution with the onset of anti-TB treatment. We did not find reports of multi-drug resistant.

\section{Medical-surgical treatment}

Thirty-nine patients (90\%) completed the treatment while $3(7 \%)$ are still with anti-TB therapy in maintenance phase and 1 (2\%) patient, despite medical recommendation, abandoned the scheme after the intensive phase. Firstline drugs (Isoniazid, Rifampicin, Ethambutol and Pyrazinamide) were used in all the cases. Clarithromycin was added to the anti-TB drugs during the intensive phase in only two of the patients while one patient conjunctively received quinolone with the anti-TB drugs in the maintenance phase. The addition of both drugs was due to the isolation of Mycobacterium bovis, strain BCG Tokyo 172 
which is resistant to pyrazinamide. Of the patients who completed the treatment, the average duration of the intensive and maintenance phases were 3.9 months and 9.1 months respectively with total treatment duration of 13 months on average. In 7 patients, the treatment was prolonged (range 15 to 24 months) due to delay in the diagnostic tests to rule out immunodeficiency and a case of concomitant meningeal Tuberculosis.

Twenty-five patients required surgical treatment. In the cases of extraaxial involvement, curettage and cryotherapy were performed in 30 cases, anterior and posterior arthrodesis in 8 cases, curettage with placement of cement in 1 case and curettage with cryotherapy and placement of glass BONE ${ }^{\mathrm{TM}}$ in 3 cases. Patients with Pott's disease were subjected to abscess drainage, debridement and stabilization. Mortality record was 0\% during the study and only 2 adverse effects during the treatment were documented.

\section{Discussion}

The diagnosis of OATB in pediatrics is a challenge due to its insidious clinical presentation. In this study, 43 cases of OATB handled under the TB unique program of the Infectious Diseases Department, National Institute of Pediatrics, Mexico City during a 20-year period were analyzed. Contrary to the national epidemiology where the pulmonary infection is the most common modality of tuberculosis, in our hospital, $85 \%$ of the cases were extrapulmonary presentations because lung TB are mostly managed in the second level of attention [5]. The presentation of OATB represented $29 \%$ of the general population, which is above the percentage in regions such as Europe, but coincides with what is reported in developing countries, particularly in Asia [6-8]. Patients $\leq 6$ years old were the most prevalent due to the high risk of progression.

The most important clinical symptom was pain in all case followed by fever. Contact with TB diagnosis was identified in $23 \%$ of the patients; however, this finding did not modify the delay in the diagnostic time with an average of 8 months (in one case, the diagnostic delay was 2 years), unlike the report of Buonsenso et al. [9], where the patients with a history of positive contact had more timely diagnosis. However, the median time of pre-diagnostic symptoms in our study of 8 months coincides with the UK cohort reported by Kenyon PC et al., with a median duration of symptoms before diagnosis of 7 months and the Taiwan cohort reported by Chin-Yun et al, with a median time of 2 months $[10,11]$.

In the present study, $\mathrm{TB}$ location was not related to the age or gender of the patients. The localization of OATB was defined as conventional only in $24 \%$, in comparison to the $42 \%$ reported in adult population by Jutte PC et al. [12]. Although this presentation might be associated to a delay diagnosis in children, more data is necessary to get a solid conclusion.

Bacteriological confirmation was poor with $85 \%$ and $71 \%$ negative culture and $\mathrm{ZN}$ staining respectively. The sensitivity of PPD in the present study was $46 \%$, which was below the range of $50 \%$ to $90 \%$ in some studies of OATB $[13,14]$. PCR test presented a sensitivity of $55 \%$ which is agreement with what was reported by WHO expert group [15]. The diagnostic method par excellence was histopathological study with a sensitivity of $97 \%$. Of the $15 \%$ positive cultures, the presence of three M. bovis BCG Tokyo 172 strains calls for attention and represents the basis of a report on the adverse effect of the vaccine. This strain contains 30 million $\mathrm{CFU} / \mathrm{ml}$ as compared to Pasteur 1173P3 sub-strain and Danesa 1331 both with 2 to 8 million CFU/ml; hence representing the highest concentration of this unit $/ \mathrm{ml}$. However, the strain presents less report of reactogenicity [16], and the presence of osteitis by BCG has a frequency of 1 case per million doses applied [17]. BCG osteitis cases have been described in countries with routine immunization programs. This finding highlights that $M$. bovis should be considered as an etiological agent in these countries. Further analysis in other countries is required to confirm this data.

All the patients in this study presented osteolytic lesions followed by abscess in $79 \%$ of the cases. However, the typical triad known as Phemister triad was only present in $9 \%$, highlighting the importance of being on alert in the presence of unique osteolytic lesions. In patients with diagnosis of Pott's disease, the use of simple radiographs may cause a delay of up to 19 months in the diagnosis; therefore, more advanced studies such as computer axial cosmography (CAT) magnetic resonance (RM) are extremely necessary [18]. In our population, the most common site of affectation was from T5 to T9 with the presence of osteolytic lesions, xiphosis and spinal cord compression in all the cases. Chest X-rays were also performed in search of concomitant pulmonary tuberculosis, finding alterations in $16 \%$ of the cases. However, it was confirmed only in two patients with sputum positive culture for M. tuberculosis which corresponds to $4 \%$ of the population and which was below the range of $6.9 \%$ to $29 \%$ reported in the literature $[19,20]$.

For the medical treatment, first-line anti-Tb drugs were used in all cases and antibiotics such as macrolides and quinolones were only added in three patients due to poor clinical evolution and isolation of $M$ bovis BCG which is resistant to pyrazinamide [20]. The average total duration of treatment was 13 months which is in line with the recommendation of WHO [21]. During the treatment, only two adverse effects 
were reported. Evolution was favorable in all the cases and mortality rate was $0 \%$ and coincides with what was reported in other studies where the frequency of $0 \%$ to $16 \%$ was found [22].

We described a significantly low treatment abandonment of $2 \%$ of one patient after the intensive phase. According to a systematic review carried out by Kruk et al. [23], a lineal increase of 7\% is estimated in the abandonment of treatment after the fourth week.

Surgical treatment in patients with vertebral involvement was necessary in $25 \%$ to $50 \%$ of the cases and in patients with diagnostic delay; this treatment may be as high as $98 \%$ [24, 25]. In the present study, all patients with Pott's disease required surgical management with drainage of abscess, debridement and stabilization due to diagnostic delay which in these cases was 9 months on average. In the patients with extraaxial involvement, $60 \%$ underwent surgical procedures such as arthrodesis, curettage, cryotherapy and placement of bone substitution. A joint approach with the Immunology Department in search of primary immunodeficiency was undertaken without finding positive results; although, some reports described a frequency of concomitant presentation of HIV with osteoarticular TB of 10 to $27 \%$, mainly in adult population [26].

\section{Conclusion}

In conclusion, our study describes the epidemiological characteristics of OATB cases in Mexican children. This data revealed a high prevalence of bone and joint TB infection. In cases of lytic bone lesions, fever and local pain, pediatric OATB should be considered. In countries with BCG immunization program, $M$. bovis should not be forgotten as an etiological agent. The low detection rate with one technique approach highlights the urgent need for more sensitive test to diagnose OATB in children.

\section{Acknowledgements}

We thank Dr. Cyril Ndidi Nwoye Nnamezie, an expert translator whose native language is English, for his help in preparing this manuscript.

\section{Authors' contributions}

NGS: Contributed to the conception and design of the work. Critically revised the manuscript for important intellectual content. Drafted manuscript. Gave final approval. MMP: Contributed to the collection, analysis, or interpretation of data. Critically revised the manuscript for important intellectual content. Drafted manuscript. Gave final approval. LXD: Contributed to the collection, analysis, or interpretation of data. Critically revised the manuscript for important intellectual content. Drafted manuscript. Gave final approval. MPR, ACD, JICB, QVC, HJO, JLCP: Contributed to the collection, analysis, or interpretation of data. Critically revised the manuscript for important intellectual content. Drafted manuscript. Gave final approval. All authors read and approved the final manuscript.

\section{Funding}

No funding was obtained from external sources for this study.

\section{Availability of data and materials}

All data generated or analyzed during this study are included in this published article. Besides, any additional data/files may be obtained from the corresponding author.

\section{Declarations}

\section{Ethics approval and consent to participate}

The study was submitted to and approved by the Institutional Ethics and Academic committee of National Institute of Pediatrics. Written informed consent was obtained from a parent or guardian for participants under 16 years old.

\section{Consent for publication}

As any identifiable information (image, face, name etc.) of participant is not revealed in the submission, for that Consent is not applicable.

\section{Competing interests}

The authors declare that there are no competing interests.

\section{Author details}

'Department of Infectious Diseases, Instituto Nacional de Pediatria (INP), Insurgentes Sur Avenue No. 3700-C, Cuicuilco District, CP 04530 Mexico City, Mexico. ${ }^{2}$ Medical Director, Instituto Nacional de Pediatria, Mexico City, Mexico. ${ }^{3}$ Department of Traumatology and Orthopedics, INP, Mexico City, Mexico. ${ }^{4}$ Laboratorio de Farmacología, Instituto Nacional de Pediatría, Avenida Imán $N^{\circ} 1$, 3rd piso Colonia Cuicuilco, CP 04530 Mexico City, Mexico. ${ }^{5}$ Department of Pharmacology, Faculty of Medicine, Universidad Nacional Autónoma de Mexico, CP 04510 Mexico City, Mexico.

Received: 4 May 2021 Accepted: 30 July 2021

Published online: 16 August 2021

\section{References}

1. Nicklisch N, Maixner F, Ganslmeier R, Friederich S, Dresely V, Meller H, et al. Rib lesions in skeleton from early neolithic sites in Central Germany: on the trail of tuberculosis at the onset of agriculture. Am J Phys Anthropol. 2012;149(3):391-404.

2. Global tuberculosis report 2017, Geneva: World Health Organization (WHO) 2017; p. 262.

3. Cruz AT, Starke JR. Pediatric tuberculosis. Pediatr Rev. 2010;31:13-25.

4. Devrim I, Aktürk H, Bayram N, Apa H, Tulumoğlu S, Devrim F, et al. Differences between pediatric extrapulmonary and pulmonary tuberculosis: a warning sign for the future. Mediterr J Hematol Infect Dis. 2014;6:e2014058.

5. Unique information platform. [Plataforma única de información/SUIVE/ DGE/SS.2015]

6. Yoon HJ, Song YG, Park WI, Choi JP, Chang KH, Kim JM. Clinical manifestations and diagnosis of extrapulmonary tuberculosis. Yonsei Med J. 2004:45:453-61.

7. Pigrau-Serrallach C, Rodríguez-Pardo D. Bone and joint tuberculosis. Euro Spine J. 2013;22(Suppl 4):S556-66.

8. Culqui-Lévano DR, Rodríguez-Valín E, Donado-Campos J. Analysis of extrapulmonary tuberculosis in Spain: 2007-2012 National Study. Enferm Infecc Microbiol Clin. 2017;35(2):82-7.

9. Buonsenso D, Lancella L, Delogu G, Krzysztofiak A, Testa A, Ranno O, et al. A twenty-year retrospective study of pediatric tuberculosis in two tertiary hospitals in Rome. Pediatr Inf Dis J. 2012;31:1022-6.

10. Kenyon P, Chapman AL. Tuberculous vertebral osteomyelitis. Findings of a 10-year review of experience in a UK centre. J Infect. 2009;59:372-3.

11. Weng $\mathrm{CH}$, Chi CH, Shih $\mathrm{P}$, Ho CM, Lin PC, Chou CH, et al. Spinal tuberculosis in non-HIV infected patients: a 10-year experience of a medical center in central Taiwan. J Microbiol Immunol Infect. 2010;43(6):464-9.

12. Jutte PC, Louenhout-Royackers JH, Borgdorf MW, van Horn JR. Increase of bone and joint tuberculosis in the Netherlands. J Bone Joint Surg. 2004;86:901-4.

13. Mulleman D, Mammou S, Griffoul I, Avimadje A, Goupille P, Valat JP. Characteristics of patients with spinal tuberculosis in a French teaching hospital. Joint Bone Spine. 2006;73:424-7. 
14. García-Lechuz J, Julve R, Alcalá L, Ruiz Serrano JM, Muñoz P, et al. Espondilitis tuberculosa o enfermedad de Pott: experiencia en un hospital general [Tuberculous spondylitis or Pott's disease: experience in a general hospital]. Enf Infect Microbiol Clin. 2002;20:5-9.

15. Expert Group Meeting Report. Using the Xpert MTB/RIF assay to detect pulmonary and extrapulmonary tuberculosis and rifampicin resistance in adults and children. Geneva: WHO; 2013.

16. Lin WL, Chiu NC, Lee PH, Huang AS, Huang FY, Chi H, et al. Management of Bacillus Calmette-Guerin osteomielitis/osteítis in immunocompetent children-a systematic review. Vaccine. 2015;33:4391-7.

17. Chiu NC, Lin MC, Lin WL, Wang SY, Chi H, Huang LM, et al. Mycobacterium Bovis BCG-associated osteomielitis/osteítis. Taiwan Emerg Infect Dis. 2015;21(3):539-40.

18. Houshian S, Poulsen S, Riegels-Nielsen PR. Bone and joint tuberculosis in Denmark. Increase due to immigration. Acta Orthop Scand. 2000;71:312-5.

19. Peto HM, Pratt RH, Harrington TA, LoBue PA, Armstrong LR. Epidemiology of extrapulmonary tuberculosis in the United States, 1993-96. Clin Infect Dis. 2009;49:1350-7.

20. American Academy of Pediatrics. Tuberculosis. In: Kimberlin DW, Brady MT, Jackson MA, Long SS, editors. Red Book: 2015 report of the committee on infectious diseases. 30th ed. Elk Grove Village: American Academy of Pediatrics; 2015. p. 805-31.
21. World Health Organization. Rapid advice: treatment of tuberculosis in children. Geneva, Switzerland: WHO Press; 2010. http://whqlibdoc.who. int/publications/2010/9789241500449_eng.pdf. Accessed 6 Feb 2012

22. Colmenero JD, Jimenez Mejias ME, Reguera JM, Palomino-Nicás J, RuizMesa JD, Márquez-Rivas J, et al. Tuberculous vertebral osteomyelitis in the new millennium: still a diagnostic and therapeutic challenge. Eur J Clin Microbiol Infect Dis. 2004;23:477-83.

23. Kruk ME, Schwalbe NR, Aguiar C. Timing of default from tuberculosis treatment: a systematic review. Trop Med Int Health. 2008;13(5):703-12.

24. Turgut M. Spinal tuberculosis (Pott's disease): its clinical presentation, surgical management, and outcome. A survey study on 694 patients. Neurosurg Rev. 2001;24:8-13.

25. Alothman A, Ziad M, Awada A, Al-Mahmood S, Sadoon A, Mohammed RM, et al. Tuberculous spondylitis: analysis of 69 cases from Arabia Saudi. Spine. 2001;26:E565-70.

26. Pertuiset E, Beaudreuil J, Liote F, Horusitzky A, Kemiche F, Richette P, et al. Spinal tuberculosis in adults. A study of 103 cases in developed country, 1980-1994. Medicine (Baltimore). 1999;78:309-20.

\section{Publisher's Note}

Springer Nature remains neutral with regard to jurisdictional claims in published maps and institutional affiliations.
Ready to submit your research? Choose BMC and benefit from:

- fast, convenient online submission

- thorough peer review by experienced researchers in your field

- rapid publication on acceptance

- support for research data, including large and complex data types

- gold Open Access which fosters wider collaboration and increased citations

- maximum visibility for your research: over 100M website views per year

At BMC, research is always in progress.

Learn more biomedcentral.com/submissions 